\title{
FEV1 (FORCE EXPIRATORY VOLUME)/FEV6 AND FEV6 AS AN ALTERNATIVE FOR FEV1/FVC (FORCED VITAL CAPACITY) AND FVC IN THE DETECTION OF OBSTRUCTIVE AIRWAY DISEASE.
}

Muhammad Faisal', Umar Usman², Saqib Musharaf ${ }^{3}$, Hafiz Amjed Hussain ${ }^{4}$, Muhammad Afzal ${ }^{5}$, Rashid Mahmood Khan ${ }^{6}$

1. MBBS, FCPS (Medicine) Senior Registrar Pulmonology DHQ Hospital, Faisalabad.

2. MBBS, FCPS (Pulmonology)

Assistant Professor Pulmonology Faisalabad Medical University, Faisalabad.

3. MBBS, FCPS (Pulmonology) Assistant Professor Pulmonology Gulab Devi Hospital, Lahore.

4. MBBS, FCPS

Assistant Professor Medical Unit-V DHQ Hospital, Faisalabad.

5. MBBS, MHM, M.Phil (Biochemistry)

Assistant Professor Medicine PMC, Faisalabad.

6. MBBS, M.Phil (Pharmacology) Senior Demonstrator PMC, Faisalabad.

Correspondence Address: Dr. Umar Usman

Assistant Professor Pulmonology Faisalabad Medical University,

Faisalabad.

drumarusman33@yahoo.com

Article received on:

$13 / 03 / 2019$

Accepted for publication:

02/09/2019

\section{INTRODUCTION}

Spirometry is frequently used to detect pulmonary functions. It measures the volume of air exhaled after full inhalation as a function of time. To detect airway obstruction and restriction spirometry is very helpful. ${ }^{1}$

Spirometric results are dependent on patient efforts and technician. In some patients it's very difficult to completely empty the lungs in order to achieve the FVC. Spirometry is used to screen COPD in high risk patient's i.e having age greater than 40 with smoking history and person having COPD symptons. Now a days it is studied that $\mathrm{FEV}_{6}$ can replace FVC.

In countries like Pakistan, as technical staff is short in number and are not well trained, especially difficult and costly, on the other hand $\mathrm{FEV}_{6}$ is cheap, and equally effective measurement. Question still remains regarding its efficacy, as universal reference equations are not available. ${ }^{2}$

Reference values to be used have become now available from the third national health and nutrition examination survey (NHANES III) including $\mathrm{LNL}$ of $\mathrm{FEV}_{6}$ and $\mathrm{FEV}_{1} / \mathrm{FEV}_{6}$ ratio and also for forced expiratory flow between $25 \%$ and $75 \%$ of maximum observed volume in first six seconds of FVC maneuver((FEF 25-75\%6). . $^{3,4}$

$\mathrm{FEV}_{1} / \mathrm{FEV}_{6}$ ration is almost equal to $\mathrm{FEV}_{1} / \mathrm{FVC}$ ratio shown by data from this study. Swamney and coworkers study showed that FEV6 is comparable with FVC in determining airway 
restriction and obstruction. ${ }^{5}$ The FEV1/FEV6 ratio can be used as a valid alternative for FEV1/FVC in the diagnosis of airway obstruction in adults when the realization of the Broncho dilatation test is limited in screening study in primary care. ${ }^{6}$

We know that the spirometry is recommended for the diagnosis and management of chronic obstructive pulmonary disease (COPD). The specialists of respiratory medicine such as the American Thoracic and European Respiratory Societies (ATS/ERS) have published guidelines on standards of spirometry.

\section{MATERIAL AND METHODS}

All the patients who were having respiratory complaints like dyspnea (shortness of breath), cough or expectorations presenting in the pulmonology department DHQ Hospital Faisalabad were included in the study and pulmonary function tests were performed. Adults with age ranges from 45 to 80 years were included. Data was collected during January 2017 to June 2017. Any patient who cannot exhale for 6 seconds, history of chest injuries; clinically relevant alterations of the physical examination of the heart and chest wall; major ECG abnormalities; pitting ankle edema; and the use of diuretics, cardiac glycosides or $\beta$-adrenergic blocking agents were excluded from study.

NHANESIII reference equation was used to determine the low-normal-limits LNL for, $\mathrm{FEV}_{1}$, FVC, $\mathrm{FEV}_{1} / \mathrm{FVC}, \mathrm{FEV}_{6}$ and $\mathrm{FEV}_{1} / \mathrm{FEV}_{6}$.

Forced vital capacity, or FVC, is defined as the volume of air in the lungs that can be exhaled following a deep inhalation. FVC is normal at or above $80 \%$ and a value below $80 \%$, shows restrictive lung disease.

Forced expiratory volume-one second (FEV1) is the measurement of volume of air that can be exhaled in one second following a deep inhalation.

FEV1/ FVC ratio is the percentage of the lung size (FVC) that can be exhaled in one second. It is calculated by dividing FEV1 with FVC. Its normal value is more than $70 \%$. Less than $70 \%$ is in obstructive lung disease.

FEV6 is the measurement of volume of air in liters that can be exhaled in six seconds following a deep inhalation.

$\mathrm{FEV}_{1} / \mathrm{FEV}_{6}$ ratio is ratio of FEV1 and FEV6; it is calculated by dividing FEV1 with FEV6. We took $72 \%$ as the cut off value for this ratio and patient with $<72 \%$ will be labeled as obstructive lung disease. Depending on severity of obstruction of airways obstructive group was further divided according to European respiratory society definition.

Patients were labeled as having airway obstruction or obstructive lung disease if $\mathrm{FEV}_{1} / \mathrm{FVC}$ ratio was below its LNL, similarly those patients with respiratory complaints and having normal $\mathrm{FEV}_{1} /$ FVC but FVC below low normal limits was labeled as having restriction or restrictive lung disease.

Spirometery was performed with Mir Spiro lab III (model 2200; Senser Mechis Yorba Lindo CA) by technicians well trained in performing pulmonary function test according to guidelines by European society of respiration. Three recordings were taken after each spirometric measurement and the spirometric measurement with the largest sum of $\mathrm{FEV}_{1}$ and FVC was taken as final. $\mathrm{FEV}_{6}$ was also taken from along with it. Spirometry flow/volume loops were conducted in accordance with American Thoracic Society (ATS) recommendations.

Sensitivity is the proportion of true positives out of all those who truly have the obstructive or restrictive lung disease. Specificity is the proportion of true negatives out of all those who truly don't have obstructive or restrictive lung disease. Positive predictive value is the proportion of true positives out of all those who are positive on FEV1/FEV6 (for obstructive disease) or FEV6 (for restrictive disease). Negative predictive value is the proportion of true negatives out of all those who are negative on FEV1/FEV6 (for obstructive disease) or FEV6 (for restrictive disease). True positives (TP) are those individuals who are 
positive on FEV1/FEV6 (for obstructive disease) or FEV6 (for restrictive disease) as well as on FEV1/FVC (for obstructive disease) or FVC (for restrictive disease). True negatives (TN) are those individuals who are negative on FEV1/FEV6 (for obstructive disease) or FEV6 (for restrictive disease) as well as on FEV1/FVC (for obstructive disease) or FVC (for restrictive disease). False positives (FP) are those individuals who are positive with FEV1/FEV6 (for obstructive disease) or FEV6 (for restrictive disease) but negative FEV1/FVC (for obstructive disease) or FVC (for restrictive disease). False negatives (FN) are those individuals who are negative on FEV1/ FEV6 (for obstructive disease) or FEV6 (for restrictive disease) but positive with FEV1/FVC (for obstructive disease) or FVC (for restrictive disease).

We used two by two $(2 \times 2)$ tables to calculate sensitivity and specificity for $\mathrm{FEV}_{1} / \mathrm{FEV}_{6}$ below its LNL as a predictor for obstruction. Similarly sensitivity and specificity were determined for FEV6 as predictor for a restrictive spirometric pattern. Positive predictive value and negative predictive value was also calculated. Female, male and total populations result was calculated. Statistical software (SPSS II.0; SPSS; Chicago IL) was used for statistical analysis.

\section{Following formulas were used}

\begin{tabular}{|c|c|}
\hline$a(T P)$ & $b(F P)$ \\
\hline$c(F N)$ & $d(T N)$ \\
\hline
\end{tabular}

Sensitivity $=a / a+c^{*} 100$

Specificity $=d / b+d^{*} 100$

Positive predictive value $=a / a+b * 100$

Negative predictive value $=d / c+d * 100$

\section{RESULTS}

In this cross sectional validation study conducted at the DHQ hospital department of chest medicine, data collected from 250 patients regarding spirometry was entered on a Performa and was later using SPSS. Due to exhalation time of less than 6 seconds in 10 patients, data of these 10 cases were excluded from the study. Rests of the 240 test cases were included in the study. We consider only 1 test per patient. NHANES III reference equation defined LLN on FEV1, FVC, and $\mathrm{FEV}_{1} / \mathrm{FVC}$ were used to determine restrictive and obstructive pattern. Depending on severity of obstruction of airways obstructive group was further divided according to European respiratory society definition. Possible normal variant (FEV $>100 \%$ predicted). Mild obstruction shown by $\mathrm{FEV}_{1}>70 \%$ to $<100$ predicted); Moderate obstruction $\mathrm{FEV}_{1}>50 \%$ to $<70 \%$ predicted) and severe obstruction by $\mathrm{FEV}_{1}<50 \%$ predicted.

Among all the cases included in the study, 144 (60\%) were men and 106 (40\%) were women.

\begin{tabular}{|l|c|c|}
\hline \multicolumn{1}{|c|}{ Gender } & Frequency & Percentage \\
\hline Male & $144 / 240$ & $60 \%$ \\
\hline Female & $106 / 240$ & $40 \%$ \\
\hline Table-I. Showing the gender distribution in the study \\
population.
\end{tabular}

Among all the patients included in our study, more than half were diagnosed to have an obstructive disease 140 out of 240 , i.e. the prevalence of obstruction in our study population was $58.33 \%$. Taking FEV1/FVC as gold standard in diagnosing obstructing lung disease, $2 \times 2$ table was used to calculate the sensitivity and specificity. Sensitivity of $\mathrm{FEV}_{1} / \mathrm{FEV}_{6}$ came to be $97.4 \%$ and specificity of $85.2 \%$ along with PPV of $96.5 \%$ and a NPV of $88.5 \%$.

When $\mathrm{FEV}_{1} / \mathrm{FVC}$ was normal in subjects $\mathrm{FEV}_{6}$ was used as alternative for FVC to determine restrictive pattern. Taking FVC as a gold standard for diagnosis of restrictive lung disease, $2 \times 2$ table was used to calculate sensitivity and specificity of FEV6, sensitivity of $96.5 \%$ and $85.71 \%$ specificity. $97.65 \%$ was PPV and $80 \%$ was NPV.

\section{DISCUSSION}

Aim of this study was to check whether FEV / $\mathrm{FEV}_{6}$ can be used instead of $\mathrm{FEV}_{1} / \mathrm{FVC}$. Results were quite satisfactory. In addition almost all of the discordant cases were close to the LNL. American thoracic society guidelines shows that LNL are variable so cannot be considered 
arbitrary limits that correctly divide patients as abnormal and normal. Subjects with value close of LNL should be calculated with caution. Diurnal, day to day differences in spirometric data can change outcome across LNL. ${ }^{7}$

Comparing with Swanney and coworkers specificity and sensitivity of ours was $85.2 \%$ and 97.4\% while theirs were $97.4 \%$ and $95.8 \%$. PPV was $96.5 \%$ as compared to $98.6 \%$ in their study and NPV in our study was $88.5 \%$ and $91.1 \%$ in theirs. Our study showed obstruction in $58.33 \%$ and $65.1 \%$ in swamney $\mathrm{cl}$ al. So it was expected to have low PPV in our study. Our study is applicable to population with airway obstruction prevalence of $58.33 \%$ (33.8\% females and $43.3 \%$ males).

Decreased total lung volume/capacity is used to diagnose restriction. American thoracic society guidelines say that when $\mathrm{FEV}_{1} / \mathrm{FVC}$ is normal and FVC is reduced suggest restrictive but not diagnosed restrictive problem. According to study by aoron and coworkers ${ }^{8}$, it can be seen that $<60 \%$ of people were actually having restriction when using total lung capacity measurement while there spirometry shows restriction. (58\% was PPV of FVC).

But NPV was $95.4 \%$ which favors that spirometry is helpful to exclude restriction. Our study show high NPV in when comparing FVC and $\mathrm{FEV}_{6}$ as a marker of restriction. So $\mathrm{FEV}_{6}$ can be used to exclude restriction.

Vandevoorde $\mathrm{J}$, et al reported after a study done to know the fixed cut-off values for FEV(1)) / FEV6 and FEV6 to see whether it can be used as an alternate of FEV(1) / FVC and FVC while dealing with suspected cases of airway obstruction and restriction, respectively, that in about eleven thousand spirometric studies in adult patients, ROC curves showed the FEV(1) / FEV(6) $<73 \%$ and $\mathrm{FEV}(6)<82 \%$ of the predicted value can be taken as alternate to $\mathrm{FEV}(1) / \mathrm{FVC}<70 \%$ and FVC $<80 \%$ predicted cut off limits in the diagnosis of obstruction and restriction, respectively. With a prevalence of obstruction of $45.9 \%$, FEV (1) / FEV (6) sensitivity and specificity were 94.4 and 93.3\%, respectively; PPV 92.2; NPV 95.2\%.
Similarly, with a prevalence of restrictive disease of $14.9 \%$, FEV (6) sensitivity and specificity were 95.9 and $98.6 \%$, respectively; PPV 92.2 and NPV $99.3 \%$, respectively. ${ }^{9}$

Stupnytska G, et al reported that after analysis of data collected from 250 spirometric tests performed in the patient with COPD, divided into smokers and non-smokers, that all of the parameters of FEV6 and FEV1/FEV6 ratio in these patients were almost similar to FVC and FEV1/FVC; and the sensitivity and specificity of FEV1/FEV6 was $92.0 \%$ and $90.1 \%$. The positive predictive value and negative predictive value was $88.6 \%$ and $92.0 \%$, respectively.

In another study, Vandevoorde $\mathrm{J}$, et al. reported, after analyzing about eleven thousand spirometric cases of white race, of age between 20-80 years with 7,010 males and 4,666 females who were able to exhale unto at least $6 \mathrm{sec}$, obstructive lung disease can be labeled if FEV1/FVC is below LLN and any patient can be labeled as having restrictive lung disease if FVC is below its LLN, in the absence of obstruction. In this study, sensitivity and specificity of FEV1/ FEV6 and FEV6 for the spirometric diagnosis of airway obstruction, FEV1/FEV6 sensitivity was 94.0\% and specificity was $93.1 \%$; the positive predictive value (PPV) and negative predictive value (NPV) were $89.8 \%$ and $96.0 \%$, respectively. The prevalence of obstruction in the entire study population was $39.5 \%$, unlike out study. Almost similar to our results were observed in this study regarding diagnosis of restrictive lung disease. FEV6 sensitivity was $83.2 \%$ and specificity was 99.6\%; the PPVs and NPVs were 97.4\% and $96.9 \%$, respectively. But prevalence of this restriction was $15.7 \%$, unlike our study. Both male and female population had equal results. They concluded that FEV1/FEV6 ratio can be used as an alternate for FEV1/FVC in the airway obstruction and FEV6 as an alternate for FVC in the diagnosis of restricted lung disease. FEV6 is more defined and is easier to achieve. ${ }^{10}$

Spirometry indices are influenced by age, height, sex, and ethnicity. ${ }^{11}$ Therefore, discovering the cut-off value of $\mathrm{FEV}_{1} / \mathrm{FEV}_{6}$ for detecting airway 
obstruction in a nationwide, representative population sample in Pakistan is worthwhile.

After review of many studies, the prevalence in smoker population of COPD is 30 to $58 \%$ if spirometry is used as diagnostic tool. So $\mathrm{FEV}_{1} / \mathrm{FEV}_{6}$ can be used instead of $\mathrm{FEV}_{1} / \mathrm{FVC}$ in population having high risk of COPD for example smoker with age greater than 45 and having respiratory symptoms. ${ }^{12,13,14}$

\section{CONCLUSION}

The results of our study clearly recommends that the ratio of forced expiratory volume in one second/forced expiratory volume in six seconds and forced expiratory volume in six seconds, both can be used as a clear alternate of forced expiratory volume in one second/forced vital capacity and forced vital capacity predicted, as fixed cut-off terms for the detection of an obstructive or restrictive spirometric pattern in adults. It's easy for subjects and for the operator specifically in older patients and subject with respiratory disease in severe form. ${ }^{2}$

\section{Annexure Abbreviations}

$\mathrm{FEV}_{6}=$ forced expiratory volume at $6 \mathrm{sec}$ of exahalation;

FET = forced expiratory time;

$\mathrm{LNL}=$ lower normal limit;

NHANES III =third National and Nutrition Examination Survey;

$\mathrm{NPV}=$ negative predictive value;

$\mathrm{PPV}=$ positive predictive value.

Copyright@ 02 Sep, 2019.

\section{REFERENCES}

1. Ferguson GT, Enright PL, Buist AS, et al Office spirometry for lung health assessment in adults: A consensus statement from the National Lung Health Education Program. Chest 2000; 117, 1146-1161.

2. García-Río F, Pino JM, Dorgham A, Alonso A, Villamor $J$. Spirometric reference equations for European females and males aged 65-85 yrs. European Respiratory Journal Sep 2004, 24 (3) 397-405.
3. Hankinson JL, Odencrantz JR, Fedan KB. Spirometric reference values from a sample of the general U.S. population. Am J Respir Crit Care Med 1999; 159,179187.

4. Hankinson JL, Crapo RO, Jensen RL. Spirometric reference values for the 6-s FVC maneuver. Chest 2003; 124, 1805-11.

5. Swanney, MP, Jensen, RL, Crichton, DA, et al FEV6 is an acceptable surrogate for FVC in the spirometric diagnosis of airway obstruction and restriction. $\mathrm{Am} \mathrm{J}$ Respir Crit Care Med2000; 162,917-9.

6. Stupnytska G. Use FEV6 and FEV1/FEV6 as alternative indicators in the diagnosis of bronchial obstruction in primary care. Euro Resp J 2013; 42: (Suppl 57) P1259.

7. Quanjer PhH, Tammeling GJ, Cotes JE. Standardized lung function testing: lung volumes and forced ventilatory flows. Eur Respir J1993; 6(suppl), 5s-40s.

8. Aaron, SD, Dales, RE, Cardinal, P How accurate is spirometry at predicting restrictive pulmonary impairment? Chest1999; 115,869-873.

9. Vandevoorde J, Verbanck S, Schuermans D, Kartounian $\mathrm{J}$, Vincken W. Obstructive and restrictive spirometric patterns: fixed cut-offs for FEV1/FEV6 and FEV6. Eur Respir J. 2006 Feb; 27(2):378-83.

10. Vandevoorde J, Verbanck S, Schuermans D, Kartounian J, Vincken W. FEV1/FEV6 and FEV6 as an alternative for FEV1/FVC and FVC in the spirometric detection of airway obstruction and restriction. Chest. 2005; 127(5):1560-4.

11. Miller MR, Hankinson J, Brusasco V, et al. Standardization of spirometry. Eur Respir J. 2005; 26(2):319-338.

12. Zieliñski J, Bednarek M. Early detection of COPD in a high-risk population using spirometric screening. Chest2001; 119,731-6.

13. Stratelis, G, Jakobsson, P, Molstad, S, et al Early detection of COPD in primary care: screening by invitation of smokers aged $\mathbf{4 0}$ to 55 years. $\mathrm{Br} \mathrm{J}$ Gen Pract2004; 54,201-6.

14. Lundbäck, B, Lindberg, A, Lindström, $M$, et al Not 15 but $50 \%$ of smokers develop COPD? Report from the Obstructive Lung Disease in Northern Sweden Studies. Respir Med2003; 97,115-122. 


\begin{tabular}{|c|c|c|c|}
\hline \multicolumn{4}{|c|}{ AUTHORSHIP AND CONTRIBUTION DECLARATION } \\
\hline Sr. \# & Author(s) Full Name & Contribution to the paper & Author(s) Signature \\
\hline 1 & Muhammad Faisal & 1st Author & \\
\hline 2 & Umar Usman & 2nd Author & $\left(\sin _{1}, i b\right.$ \\
\hline 3 & Saqib Musharaf & 3rd Author & Umer \\
\hline 4 & Hafiz Amjed Hussain & 4th Author & \\
\hline 5 & Muhammad Afzal & 5th Author & Miffed \\
\hline 6 & Rashid Mahmood Khan & 6th Author & \\
\hline
\end{tabular}

